\title{
$A C E$ Gene Variant Causing High Blood Pressure May Be Associated With Medication-related Jaw Osteonecrosis
}

\author{
CHRISTOS YAPIJAKIS $^{1,2}$, VERONICA PAPAKOSTA ${ }^{1}$ and STAVROS VASSILIOU ${ }^{1}$ \\ ${ }^{1}$ Department of Oral \& Maxillofacial Surgery, School of Medicine, \\ National and Kapodistrian University of Athens, Attikon Hospital, Athens, Greece; \\ ${ }^{2}$ Department of Molecular Genetics, Cephalogenetics Diagnostic Center, Athens, Greece
}

\begin{abstract}
The association of the high blood pressure D variant of the angiotensin-converting enzyme (ACE) gene with medication-related jaw osteonecrosis (MRONJ) is described in two Greek patients. The first patient, a 73-yearold man, took zolendronate, $4 \mathrm{mg} / 100 \mathrm{ml} \mathrm{IV}$ once per month for two years for prostate cancer and bone metastases. Three months after drug discontinuation, extraction of the first premolar was performed. After the intervention, he suffered from osteonecrosis of the mandible. He presented with hypertension and genetic testing revealed that he was homozygous for the high blood pressure $D$ variant of the ACE gene. The second patient, a 65 years old woman, took denosumab, $120 \mathrm{mg}$ subcutaneously once per month for 6 months for possible bone metastases from breast cancer. Three months after extraction of the first molar, she suffered from MRONJ. He also presented with hypertension and genetic testing revealed that she had the high blood pressure $D$ variant of the ACE gene in a heterozygous state, which moderately predisposes to hypertension. To our knowledge, this is the first report indicating that genetic predisposition to hypertension may increase risk for MRONJ.
\end{abstract}

In 2014, the American Association of Oral and Maxillofacial Surgeons (AAOMS) proposed the term "medication-related osteonecrosis of the jaw" (MRONJ), to include according to certain criteria all cases of medication associated jaw osteonecrosis, in addition to those due to bisphosphonate

This article is freely accessible online.

Correspondence to: Ass. Prof. Stavros Vassiliou, MD, DDS, Ph.D., Department of Oral \& Maxillofacial Surgery, School of Medicine, National and Kapodistrian University of Athens, Attikon Hospital, Rimini 1, Athens 12462, Greece. Tel: +30 2105831544, Fax: +30 2105831545, e-mail: stvasil@med.uoa.gr

Key Words: Angiotensin-converting enzyme, bisphosphonateassociated osteonecrosis of the jaw, denosumab, bisphosphonates, hypertension. drugs (1). There are several genetic factors that may influence the risk for MRONJ.

A common genetic factor associated with endogenous hypertension is the insertion/deletion (I/D) mutation in the gene encoding angiotensin-converting enzyme ( $A C E)$ which regulates blood pressure by converting angiotensin $\mathrm{I}$ to angiotensin II $(2,3)$. The D allele increases plasma ACE levels leading to vasoconstriction and high blood pressure. Therefore, D/D homozygotes display high angiotensin II levels, I/I homozygotes have lower levels, while I/D heterozygotes display intermediate angiotensin II levels and modestly high blood pressure, lower than D/D homozygotes (4-6).

Here, two patients with MRONJ that had hypertension due to the presence of the high blood pressure associated $\mathrm{D}$ allele in their $A C E$ gene are described. The first patient had received bisphosphonates for treatment of metastases from prostate cancer. The second patient had received denosumab for neoplastic disease in bone marrow, possibly a breast cancer metastasis. To our knowledge, this is the first report that indicates a possible association of $A C E$ I/D polymorphism with medication-related jaw osteonecrosis.

\section{Case 1}

A 73-year-old Caucasian man of Greek origin reported a detailed four generations family history that did not reveal any other cases of idiopathic thrombosis (Figure 1). He was treated with zolendronate (sol.zometa $4 \mathrm{mg} / 100 \mathrm{ml}$, Novartis Hellas, Metamorfosi, Greece) once per month for two years for prostate cancer and bone metastases. Three months after drug discontinuation, extraction of the left first premolar was performed. After the extraction, he suffered from extensive submental abscess. Computed tomography (CT) revealed osteolytic and osteosclerotic lesions in the mandible (Figure 2). The submental collection was drained and a bony lesion partial biopsy was performed. The histological examination showed jaw osteonecrosis with presence of actinomycetes, but was negative for malignancy. Antimicrobial therapy was 


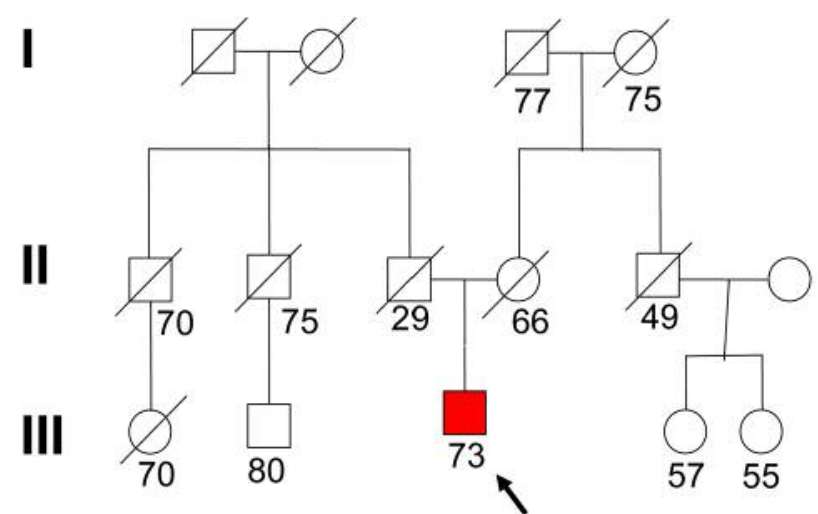

Figure 1. Pedigree of Case 1. The index patients are shown by arrows, while thrombosis-related incidents are shown in dark colour.

administered; moxifloxacin $400 \mathrm{mg}$ p.o. once daily for 4 weeks and metronidazole $500 \mathrm{mg}$ p.o. three times a day for two weeks. The patient is scheduled to undergo a second surgical treatment of bone lesions.

Genetic testing was performed on a sample of total DNA, isolated from white blood cells. Thrombophilia associated mutations FV Leiden (G1691A), FII G20210A and MTHFR C677T, as well as hypertension associated variant $A C E \mathrm{I} / \mathrm{D}$ were examined with standard molecular methodology as previously described $(7,8)$.

No mutations were detected for the above-mentioned genes of thrombophilia, however, the $\mathrm{D}$ variant of the $A C E$ gene was identified in homozygocity, which strongly predisposes to hypertension.

\section{Case 2}

A 65-year-old Caucasian woman of Greek origin reported that she took $120 \mathrm{mg}$ denosumab (Xgeva, Amgen Europe B.V, Minevum 7061 NL-481724 Breda, Holland) subcutaneously once per month for 6 months for possible bone metastases from breast cancer. The detailed family history showed autosomal-dominant inheritance of idiopathic thrombosis (Figure 3). Extraction of the right first molar was performed. Three months later she was admitted to our clinic with osteonecrosis on the right side of the lower jaw. CT scan showed osteosclerotic lesions in the right mandible with periosteum subduction (Figure 4). Antimicrobial therapy was administered; ciprofloxacin $500 \mathrm{mg}$ p.o. twice daily and metronidazole $500 \mathrm{mg}$ p.o. three times a day. Hypertension was noticed in this patient, too. Surgical debridement of the lesion was performed. The histological examination showed jaw osteonecrosis, while was negative for malignancy.

Genetic testing was performed, as in Case 1. No mutation was observed in the $F V, F I I$ and MTHFR genes. On the other

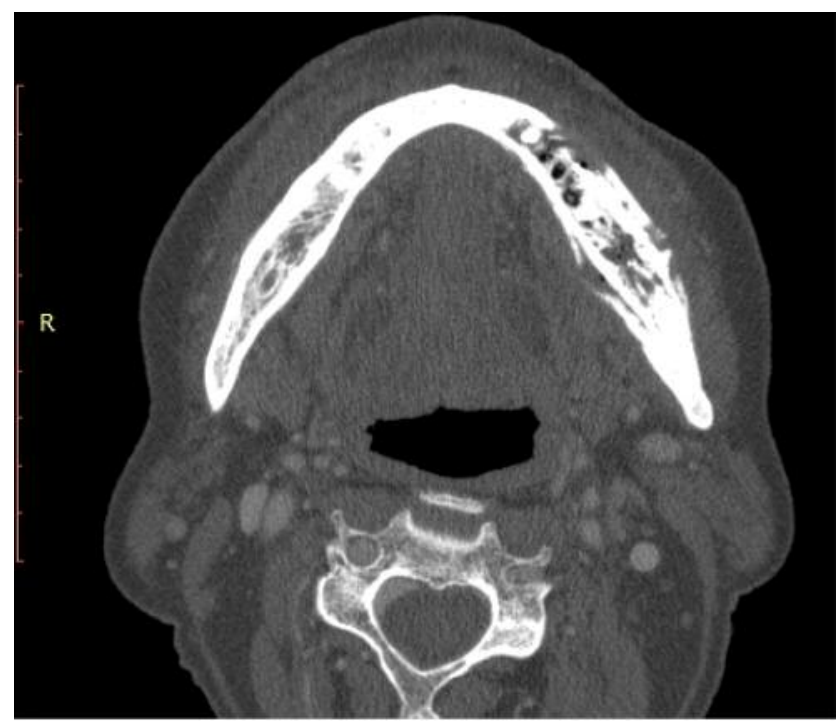

Figure 2. CT scan: Osteolytic and osteosclerotic lesions in the middle and left in the lower jaw.

hand, a heterozygous I/D mutation was found in the $A C E$ gene, which moderately predisposes to hypertension.

\section{Discussion}

Common drugs used in the treatment of bone metabolic diseases and cancer bone metastases may cause MRONJ, that poses a challenge in craniofacial surgery. The occurrence of MRONJ may be either spontaneous or following dentoalveolar surgery. Typical complications of MRONJ may include painful exposed bone, pathological fractures, extraoral fistula, and local infections. Rarely, certain complications may be life-threatening, such as a rare case of bacterial embolism in the internal jugular vein after a MRONJ-induced submandibular abscess resulting in bacterial sepsis, multi-organ failure syndrome, and death (9).

It is well known that hypertension is a systemic condition and an endogenous risk factor for jaw osteonecrosis related to medication (10). There are several reports of patients with MRONJ who had hypertension as a coexisting condition with or without the intake of corticosteroids (11). The incidence of MRONJ in cancer patients receiving biphosphonates or denosumab may be increased up to $20 \%$ (12). The incidence may be even higher when the patients have combined risk factors, such as type and duration of medication, concomitant medications, comorbidities (hypertension, dyslipidemia, diabetes etc.), lifestyle behaviors (smoking, obesity etc.), as well as genetic predisposition for certain conditions (e.g. previously known for thrombophilia). 


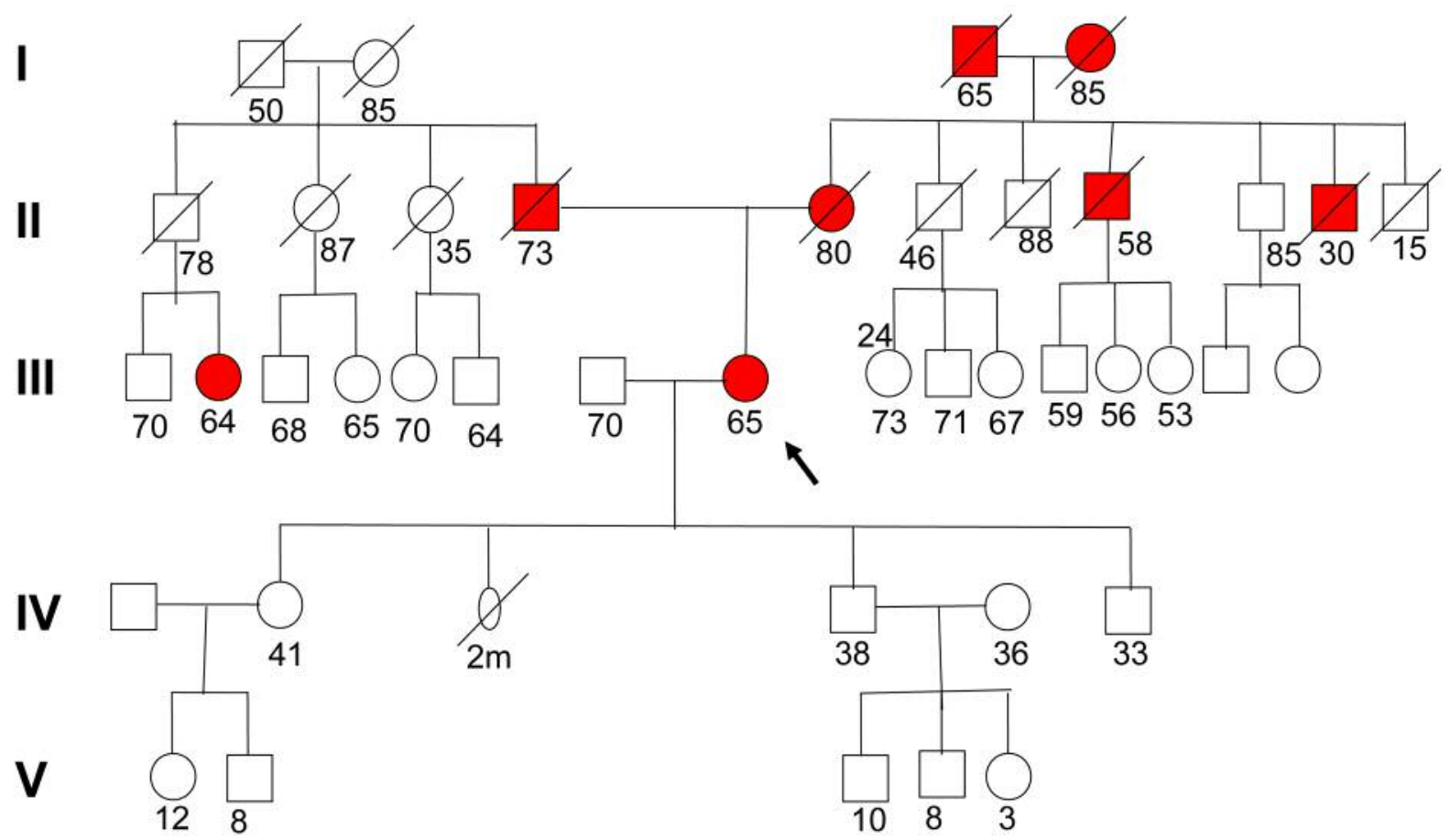

Figure 3. Pedigree of Case 2. The index patients are shown by arrows, while thrombosis-related incidents are shown in dark colour.

The two cases presented here indicate that genetic predisposition to hypertension may increase the risk for MRONJ. Therefore, genetic testing for $A C E \mathrm{I} / \mathrm{D}$ and hypertension treatment may be considered before administration of certain drugs that are related to osteonecrosis.

\section{Conflicts of Interest}

There is no conflict of interest to declare regarding this study.

\section{References}

1 Ruggiero SL, Dodson TB, Fantasia J, Goodday R, Aghaloo T, Mehrotra B and O'Ryan F: American Association of Oral and Maxillofacial Surgeons position paper on medication-related osteonecrosis of the jaw-2014 update. J Oral Maxillofac Surg 72: 1938-1956, 2014

2 Vairaktaris E, Vassiliou S, Avgoustidis D, Stathopoulos P, Toyoshima $\mathrm{T}$, and Yapijakis $\mathrm{C}$ : Bisphosphonate-induced avascular osteonecrosis of the mandible associated with a common thrombophilic mutation in the prothrombin gene. J Oral Maxillofac Surg 67: 2009-2012, 2009.

3 Yapijakis C, Koronellos N, Spyridonidou S, Vylliotis A, Avgoustidis D, Goutas N, Vlachodimitropoulos D and Vairaktaris E: Association of angiotensin-converting enzyme gene insertion/deletion polymorphism with decreased risk for basal cell carcinoma. Arch Dermatol Res 305: 333-339, 2013.

4 McKenzie CA, Julier C, Forrester T, McFarlane-Anderson N, Keavney B, Lathrop GM, Ratcliffe PJ and Farrall M:

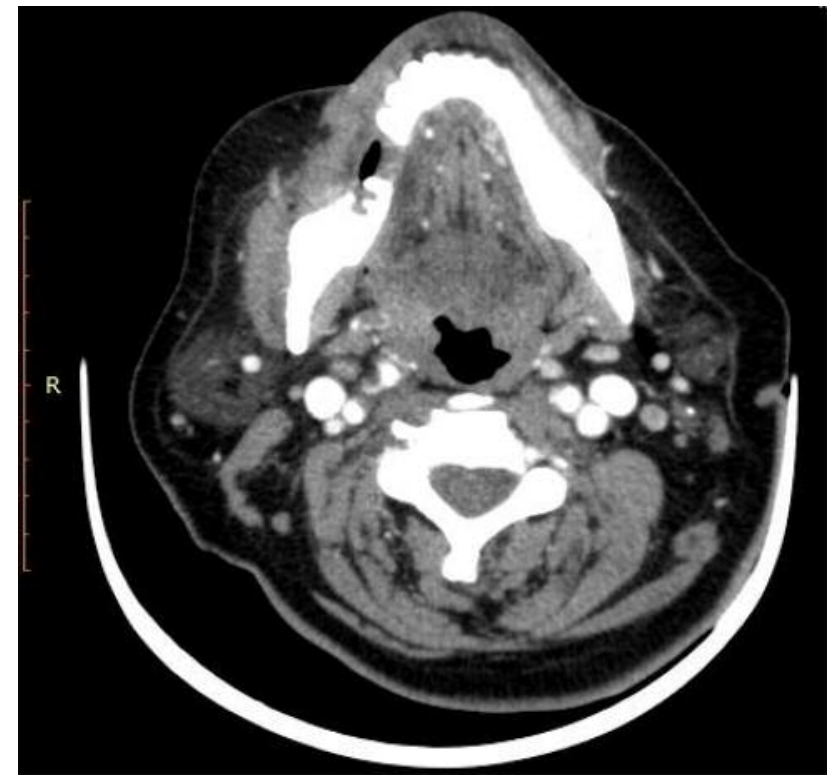

Figure 4. CT scan: Osteosclerotic lesions in the right mandible with the periosteum subduction.

Segregation and linkage analysis of serum angiotensin I-converting enzyme levels: Evidence for two quantitative-trait loci. Am J Hum Genet 57: 1426-1435,1995. 
5 Lemes VA, Neves AL, Guazzelli IC, Frazzato E, Nicolau C, Correa-Giannella M.L, Velho G and Villares SM: Angiotensin converting enzyme insertion/deletion polymorphism is associated with increased adiposity and blood pressure in obese children and adolescents. Gene 532: 197-202, 2013.

6 Kumari S, Sharma N, Thakur S, Mondal PR and Saraswathy $\mathrm{KN}$ : Beneficial role of $\mathrm{D}$ allele in controlling ACE levels: a study among Brahmins of north India. J Genet 95: 291-295, 2016.

7 Yapijakis C, Serefoglou Z, Nixon AM, Vylliotis A, Ragos V and Vairaktaris E: Prevalence of Thrombosis-Related DNA Polymorphisms in a Healthy Greek Population. In Vivo 26: 1095-1102, 2012.

8 Yapijakis, C, Serefoglou Z and Voumvourakis C: common gene polymorphisms associated with thrombophilia. in thrombosis, atherosclerosis and atherothrombosis - new insights and experimental protocols. Mojca Bozic-Mijovski (ed.). InTech Publications, Rijeka, Croatia, pp. 83-103, 2015.

9 Kaehling C, Streckbein P, Schmermund D, Henrich M, Burchert D, Gattenloehner S, Howaldt HP and Wilbrand JF: Lethal cervical abscess following bisphosphonate related osteonecrosis of the jaw. J Craniomaxillofac Surg 42: 1203-1206, 2014.
10 Assaf AT, Smeets R, Riecke B, Weise E, Gröbe A, Blessmann M, Steiner T, Wikner J, Friedrich RE, Heiland M, Hoelzle F and Gerhards F: Incidence of bisphosphonate-related osteonecrosis of the jaw in consideration of primary diseases and concomitant therapies. Anticancer Res 33: 3917-3924, 2013.

11 Izzotti A, Menini M, Pulliero A, Dini G, Cartiglia C, Pera P and Baldi D: Biphosphonates-associated osteonecrosis of the jaw: the role of gene-environment interaction. J Prev Med Hyg 54: 138145, 2013.

12 Lo JC, O'Ryan FS, Gordon NP, Yang J, Hui RL, Martin D, Hutchinson M, Lathon PV, Sanchez G, Silver P, Chandra M, McCloskey CA, Staffa JA, Willy M, Selby JV and Go AS: predicting risk of osteonecrosis of the jaw with oral bisphosphonate exposure I: Prevalence of osteonecrosis of the jaw in patients with oral bisphosphonate exposure. J Oral Maxillofac Surg 68: 243-253, 2010.

Received November 4, 2018

Revised December 22, 2018

Accepted December 27, 2018 